\title{
Charcot-Marie-Tooth disease type 4B2
}

INSERM

\section{Source}

INSERM. (1999). Orphanet: an online rare disease and orphan drug data base. CharcotMarie-Tooth disease type 4B2. ORPHA:99956

Charcot-Marie-T ooth disease type 4B2 (CMT4B2) is a subtype of Charcot-Marie-Tooth type 4 characterized by a severe, early childhood-onset of demyelinating sensorimotor neuropathy, early-onset glaucoma, focally folded myelin sheaths in the peripheral nerves, severely reduced nerve conduction velocities, and the typical CMT phenotype (i.e. distal muscle weakness and atrophy, sensory loss, and frequent pes cavus). Severe visual impairment leading to visual loss has also been reported. 